\title{
Design and development of a tractor mounted hydraulic operated ladder
}

\section{R. Thiyagarajan and A. Tajuddin}

Received : 21.11.2017; Revised : 01.02.2018; Accepted : 10.02.2018

See end of the Paper for authors' affiliation

Correspondence to :

R. Thiyagarajan Regional Research Station (T.N. A.U.), Paiyur (T. N.) India

Email : thiyagarajanmtech@ gmail.com
- ABSTRACT : A tractor-mounted hydraulic operated ladder was designed and developed to reduce the harvesting /pruning cost, increase the harvesting/pruning efficiency and enhance the overall productivity of mango orchards. The design and drawing of hydraulic ladder was made and theoretical analysis of the tractor mounted hydraulic operated ladder was carried out by finite element method, using solid works software for finding the stress and stability of the hydraulic ladder and stress under static load for the hydraulic ladder. It was observed that the variations in the resultant forces are minimum for different heights $(6,810 \mathrm{~m})$, different angle of rotation from 0 $180^{\circ}$ at an interval of 45 and different varying loads $75,150,225$ and $300 \mathrm{~kg}$, respectively. It is considered to be in a state of stability when no sign of overturning is evident with the hydraulic ladder in operation. The maximum stress observed in the hydraulic ladder for, $8 \mathrm{~m}$ and $10 \mathrm{~m}$ height with different loads and different angle of rotation is $96.64 \mathrm{~N} / \mathrm{mm}^{2}$ which is less than the yielding stress which is $220.59 \mathrm{~N} / \mathrm{mm}^{2}$. The developed system is attached to the rear of a minimum $45 \mathrm{hp}$ agricultural tractor. System's power source is the tractor hydraulic system. The hydraulic ladder has the capability to lift a service worker and the required tools to the crown zone as high as 10 meters. The hydraulic ladder consists of a stabilizing system (four cylinders) on both side of the trailer for supporting, stability and safety for the operators at the time of operation.

- KEY WORDS : Hydraulic ladder, Design, Stability, Tractor mounted, Stress, Stabilizing system

- HOW TO CITE THIS PAPER : Thiyagarajan, R. and Tajuddin, A. (2018). Design and development of a tractor mounted hydraulic operated ladder. Internat. J. Agric. Engg., 11(1) : 1-12, DOI: 10.15740/ HAS/IJAE/11.1/1-12. 